\title{
Phthalate Ester Pollution in Urban Soil of Beijing, People's Republic of China
}

\author{
X. H. Li, ${ }^{1}$ L. L. Ma, ${ }^{1}$ X. F. Liu, ${ }^{1}$ S. Fu, ${ }^{1}$ H. X. Cheng, ${ }^{2}$ X. B. Xu ${ }^{1}$ \\ ${ }^{1}$ State Key Laboratory of Environmental Chemistry and Ecotoxicology, Research \\ Center for Eco-Environmental Sciences, the Chinese Academy of Sciences, \\ Post Office Box 2871, Beijing 100085, People's Republic of China \\ ${ }^{2}$ Institute of Geophysical and Geochemical Exploration, Langfang, 065000, \\ People's Republic of China
}

Received: 21 December 2005/Accepted: 31 May 2006

Phthalate esters (PAEs) are synthetic compounds, which have been used as pesticide carriers or insect repellents, in cosmetics, fragrances, lubricants and defoaming agent. However, by far they are mostly utilized as additives in plastic products. Today, the total global annual output is estimated to be around several million tons and will continue to increase. Since they are only physically bound to the plastic structure, PAEs can leach out from the plastic products during use and after disposal. As a result, PAEs have become ubiquitous contaminants (Stales et al. 1997) and are often found in water, soil, air and biological fluids/tissues (Latini, 2005). Due to the suspected endocrine disrupting potential, PAEs have been listed as priority pollutants by the US EPA (Keith and Telliard 1979). Three phthalates (diethyl, di-n-buthyl-, and di-n-octyl phthalate esters) are also listed in the black list of China's water priority pollutants by China National Environmental Monitoring Center.

Due to the widespread application of plastic products in urban areas, PAEs have been the most abundant compounds in various environmental matrix compared to other organic pollutants (Du et al. 2004; Liu et al. 2004). It was estimated that there are as much as 4-12 kg/d PAEs released to the urban environment and even over 42-100 kg/d PAEs to some metropolis in China, e.g. Beijing and Shanghai. As for Beijing, it was reported that PAEs were in the range of $0.12-10.10 \mu \mathrm{g} / \mathrm{L}$ in the ground water (Wei et al. 1986), 1.34-2.80 mg/kg in soil (Ma et al. 2003), $1-100 \mathrm{ng} / \mathrm{m}^{3}$ in the atmosphere (Zhao et al. 1987; Zeng et al. 2003) and 25-77 $\mathrm{mg} / \mathrm{kg}$ in municipal sludge (Du et al. 2004). These studies above indicated that PAEs have caused serious pollution to the environment of Beijing.

Organic pollutants in soil can enter into the atmosphere by evaporation or migrate into water by rain etc., thus causing direct or indirect exposure of human to these pollutants. Therefore, it was crucial to monitor these pollutants in soil. However, the current polluted situation of soil by PAEs in Beijing was known limited, which will be an obstacle for the development of Beijing. Our study was aimed to investigate the residual levels of PAEs in urban soil of Beijing, and to assess their potential eco-toxicological effect on the environment. It was expected that our studies be helpful for the rapid urbanization and industrialization of Beijing. 


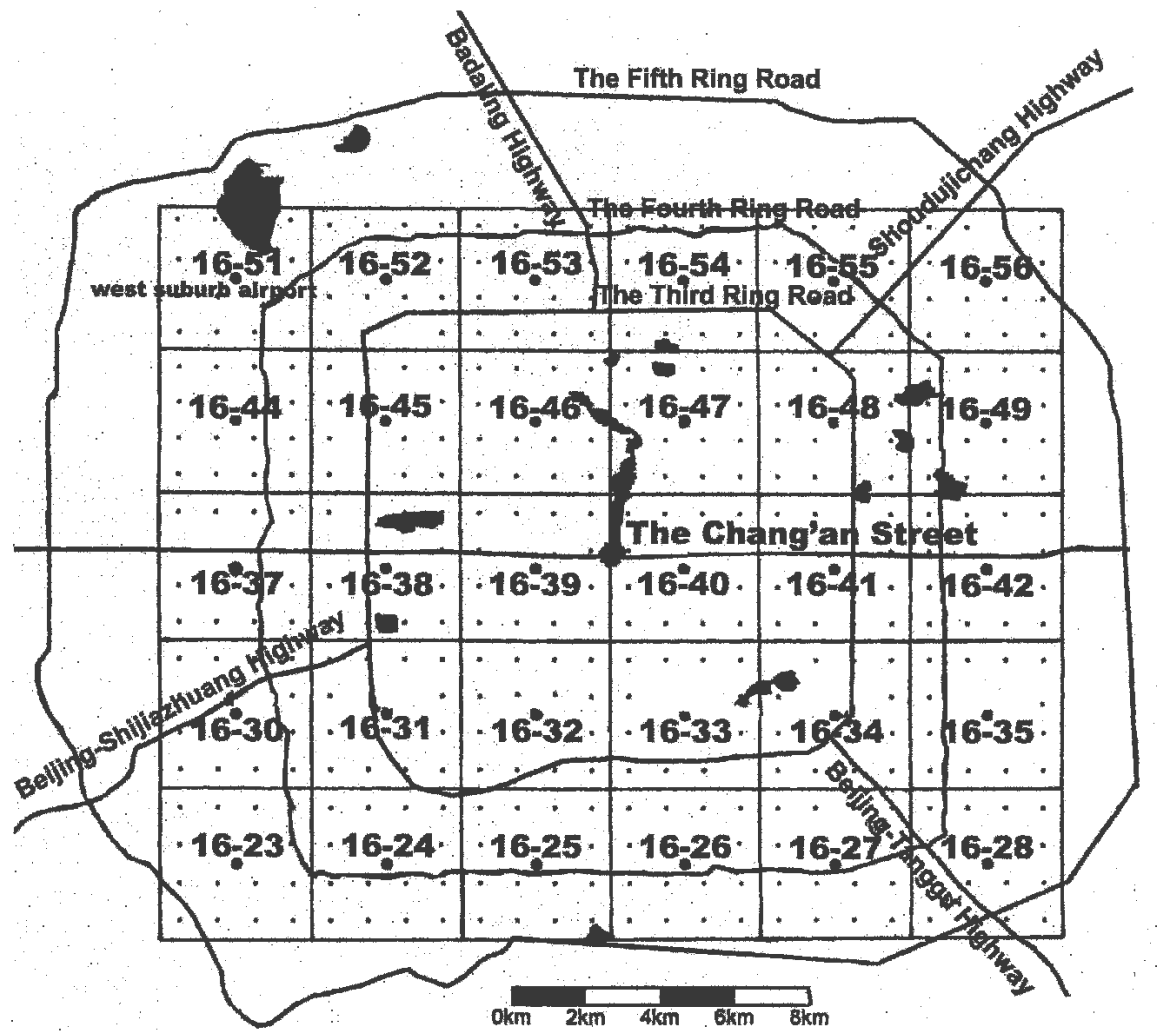

Figure 1. Geographic location of samples sites

\section{MATERIALS AND METHODS}

The mixed standard solution of six EPA phthalates (Dimethyl phthalate (DMP), Diethyl phthalate (DEP), Di-n-butly phthalate (DnBP), Di-iso-butly phthalate (DiBP), Benzylbutyl phthalate (BBP), Di-2-ethlyhexyl phthalate (DEHP), Di-n-octyl phthalate (DOP), $1000 \mu \mathrm{g} / \mathrm{mL}$ ) were purchased from Aldrich (WIS, USA) and further diluted to obtain the desired concentration. The surrogate, dicyclohexyl phthalate (DCP), was purchased from Supelco (Bellefonte, PA, USA) and was prepared to the desired concentration $(2.000 \mathrm{mg} / \mathrm{L})$. All solvents were of analytical purity (Beijing Chemical Factory, China) and were redistilled in all-glass system before use. Florisil (60-100 mesh) from Supelco (Bellfonte, USA) was activated in drying oven at $130{ }^{\circ} \mathrm{C}$ for $16 \mathrm{~h}$. Anhydrous sodium sulfate $\left(\mathrm{Na}_{2} \mathrm{SO}_{4}\right.$, analytical purity, Beijing Chemical Factory, China) was heated at 600 ${ }^{\circ} \mathrm{C}$ for $12 \mathrm{~h}$. To avoid the contamination of PAEs during the experiment, glassware was prepared successively in the following order: washed with acetone and water, soaked in $5 \% \mathrm{~K}_{2} \mathrm{Cr}_{2} \mathrm{O}_{4}$ sulfuric acid solution overnight, washed with water and distilled water in turn, dried in oven and rinsed with acetone and hexane just before use. 
Soil at 30 different locations of urban areas in Beijing was sampled. The studied area was divided into regular grids of $4 \times 4 \mathrm{~km}^{2}$, where topsoil samples $(5-30 \mathrm{~cm})$ were collected. Each of the composite soil samples was made of 16 sub-samples obtained in a $1 \times 1 \mathrm{~km}^{2}$ grid using a stainless steel hand auger. The detailed sampling locations are shown in Figure 1. The soil was air-dried at room temperature, thoroughly mixed, sieved to 30 mesh and stored in glass bottles at -4 ${ }^{\circ} \mathrm{C}$ before further processing. The remaining water content in the soil was determined gravimetrically after drying individual composite sample at $105{ }^{\circ} \mathrm{C}$ for $12 \mathrm{~h}$. All the results were reported as dried weight.

$5 \mathrm{~g}$ of soil was ground with $\mathrm{Na}_{2} \mathrm{SO}_{4}$ into free flowing powder. The sample was ultrasonically extracted in centrifuge tube with $30 \mathrm{~mL}$ of $1 / 1(\mathrm{v} / \mathrm{v})$ acetone/hexane for $5 \mathrm{~min}$ and then the extact was separated by centrifugation. The process was repeated for three times. The solvents were combined and evaporated, then hexane was added as solvent. The concentrated extract was transferred to chromatograph column ( $30 \mathrm{~cm} \times 10 \mathrm{~mm}$ I.D.) containig $5 \mathrm{~g}$ of activated Florisil with $1 \mathrm{~g}$ of $\mathrm{Na}_{2} \mathrm{SO}_{4}$ on the column top. The Florisil was soaked in hexane and was filled in the column. The concentrated extract was transferred to the column top and was eluted by $50 \mathrm{~mL}$ hexane-diethyl ether $(90 / 10$, v/v) and followed by $50 \mathrm{~mL}$ of hexane-diethyl ether $(40 / 60, \mathrm{v} / \mathrm{v})$. The second fraction was collected and was adjusted to $0.2 \mathrm{~mL}$ for $\mathrm{GC}$ analysis.

Quantification of Phthalate Esters (PAEs) was carried out with an Agilent 6890 gas chromatograph equipped with flame ionization detector (GC-FID). The separation of compounds was performed on a fused silica capillary column (DB-5, $30 \mathrm{~m} \times 0.25 \mathrm{~mm}$ I.D., and $0.25 \mu \mathrm{m}$ film thickness). The carrier gas was nitrogen with a flow of $1.2 \mathrm{~mL} / \mathrm{min}$. The injector and detector temperature were $225^{\circ} \mathrm{C}$ and $310{ }^{\circ} \mathrm{C}$, respectively. The $\mathrm{GC}$ oven temperature was programmed as followed: initial temperature $60{ }^{\circ} \mathrm{C}$ held for $2 \mathrm{~min}$, increased to $280{ }^{\circ} \mathrm{C}$ at a rate of $10{ }^{\circ} \mathrm{C}$ $/$ min held for $2 \mathrm{~min}$. $1 \mu \mathrm{L}$ of sample was injected in splitless mode. Peak identification of PAEs was made by comparison of retention times with corresponding standards. Quality control was based on the following procedures. Method blank was firstly run. The matrix blanks, the recoveries of PAEs and the limits of detection were based on the measures of the deep layer soil samples from the rural area of Beijing, which was hardly any interference for the target analytes. The average recoveries of PAEs were in the range of $65-123 \%$ with $3-15 \%$ relative standard deviations. Before the extraction, the soil sample was spiked with known amounts of DCP as surrogate to compensate for the losses of PAEs. Recoveries for DCP were from $76 \%$ to $113 \%$ (mean: $87 \%$ ) and the values were satisfactory and no correction was applied to the samples. The limits of detection (LODs) for PAEs as three times response of signal-to-noise in matrix blank samples, ranged from $2.0 \mathrm{ng} / \mathrm{g}$ for DEP to $19.7 \mathrm{ng} / \mathrm{g}$ for DEHP. All data were blank corrected. Correlation analysis was performed with SPSS 11.5 for Windows. For the spatial distribution of PAEs, Surface Mapping System (Ver. 7.0, Golden software, CO, USA) and Mapinfo Professional 6.5 SCP were used to draw the contour map. 
Table 1. Statistics description of PAEs in soil of Beijing ( $\mathrm{mg} / \mathrm{kg}$, dw).

\begin{tabular}{lcccccc}
\hline & Minimum & Maximum & Mean & Median & Geometric mean & Std.deviation \\
\hline DMP & nd & 0.067 & 0.010 & 0.008 & 0.008 & 0.012 \\
DEP & nd & 0.252 & 0.016 & 0.005 & 0.007 & 0.045 \\
DiBP & 0.149 & 0.936 & 0.311 & 0.246 & 0.274 & 0.182 \\
DnBP & 0.279 & 3.817 & 0.790 & 0.463 & 0.611 & 0.753 \\
BBP & nd & 0.060 & 0.029 & 0.033 & 0.017 & 0.016 \\
DEHP & 0.170 & 6.491 & 1.875 & 1.388 & 1.388 & 1.483 \\
DOP & nd & 0.172 & 0.031 & 0.012 & 0.014 & 0.045 \\
$\Sigma 7$ PAEs & 0.716 & 8.333 & 3.170 & 2.465 & 2.718 & 1.890 \\
$\sum$ 6 EPA-PAEs & 0.508 & 7.959 & 2.751 & 2.197 & 2.284 & 1.821 \\
\hline nd: No detectable & & & & & &
\end{tabular}

nd: No detectable

\section{RESULTS AND DISCISSION}

The statistics description of PAEs residues in soil is shown in Table 1. The concentration of the total PAEs ( $\Sigma 7$ PAEs) ranged from $0.716-8.333 \mathrm{mg} / \mathrm{kg}$ with the standard deviation of $1.890 \mathrm{mg} / \mathrm{kg}$. The concentration of $\Sigma 6$ EPA-PAEs (equivalent sum of DMP, DEP, DnBP, BBP, DEHP, DOP) was in the range of $0.508-7.959 \mathrm{mg} / \mathrm{kg}$ with $1.821 \mathrm{mg} / \mathrm{kg}$ as the standard deviation. The spatial distribution of $\sum 7$ PAEs was described by contour map in Figure 2 . It seemed that concentration of PAEs in the studied areas was mainly in the range of $2-4 \mathrm{mg} / \mathrm{kg}$. One area with the higher level of PAEs was located around the east third-ring Road, probably relating with several plastic factories around there. Another was in the center of urban area, probably resulting from the densely anthropogenic activities.

I6 EPA-PAEs in the studied area accounted for $87 \%$ of the total seven PAEs, while both of DEHP and DnBP were the major composition in all samples collected. The concentration of DEHP was in the range of $0.170-6.491 \mathrm{mg} / \mathrm{kg}$ with $1.857 \mathrm{mg} / \mathrm{kg}$ as mean. The concentration of DnBP was in the range of $0.279-3.817 \mathrm{mg} / \mathrm{kg}$ with $0.790 \mathrm{mg} / \mathrm{kg}$ as mean. To our knowledge, limited data about DiBP in soil have been previously reported, while the compound in all of the samples in this studied area was detected out and ranged from $0.149 \mathrm{mg} / \mathrm{kg}$ to $0.936 \mathrm{mg} / \mathrm{kg}$ with $0.311 \mathrm{mg} / \mathrm{kg}$ as mean. Another important compound, DOP, was not dominant in the study area in the range of nd- $0.172 \mathrm{mg} / \mathrm{kg}$ with the mean of $0.031 \mathrm{mg} / \mathrm{kg}$. The high fraction of DEHP and DnBP was similar to the composite characteristic of PAEs detected in various environmental matrix (Zhao et al. 1987; Ma et al. 2005; Zhang et al. 2003) and in plastic products (Sun et al. 2002; Wang et al. 2004) in China. This was in consistent with the fact that there are the more abundant usage of DEHP, DnBP and DiBP as plastic additives in China (Yu et al. 1997). 


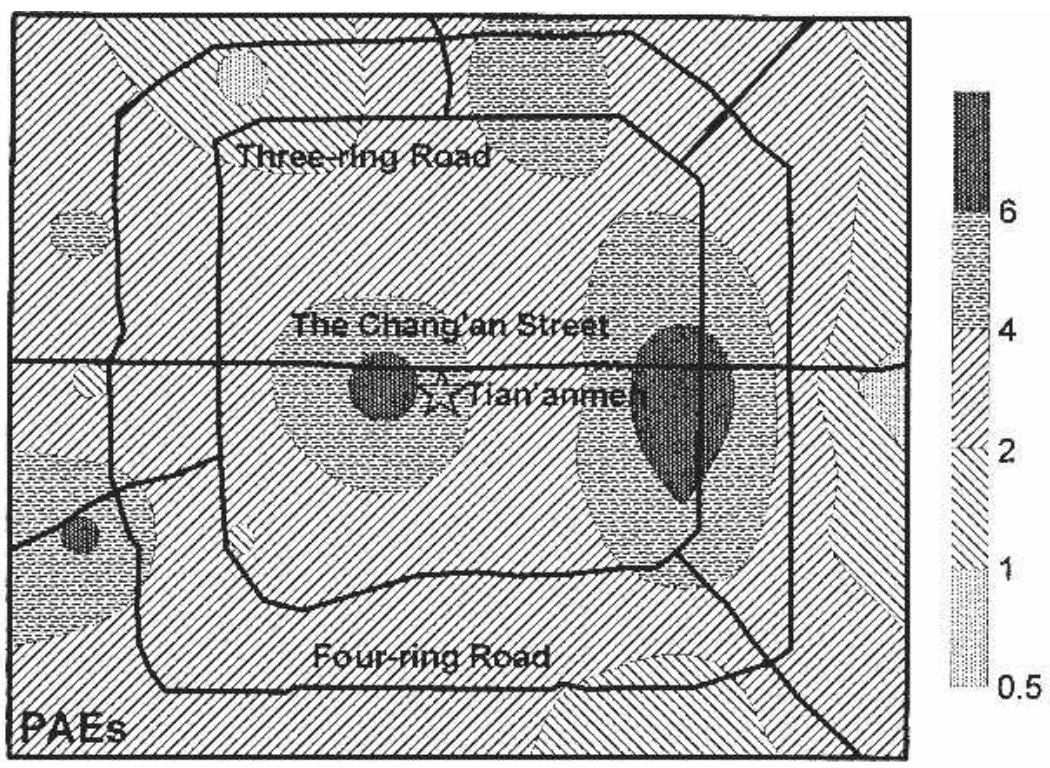

Figure 2. The spatial distribution of $\sum 7$ PAEs $(\mathrm{mg} / \mathrm{kg})$

In this study, DEHP, DnBP and DiBP accounted for $59 \%, 25 \%$ and $10 \%$ of the total PAEs, respectively. The levels were, in general, in the order of DEHP > DnBP $>$ DiBP. The predominance of DEHP agreed with the fact that DEHP was most widely employed phthalate in PVC (Shanker et al. 1985). However, it was different in the sites of 16-51,16-52 and 16-53 with more abundant DnBP compared to DEHP. Correlation analysis of PAEs showed that there existed a good correlation between DEHP and DiBP $(p<0.05)$, and a poor correlation between DnBP and DEHP or DnBP and DiBP, probably reflecting the similar source of DEHP and DiBP, and the source difference of DnBP from DEHP and DiBP.

To understand contamination situation of soil in Beijing, the levels of three most important compositions, DEHP, DnBP and DOP, were compared to those in soil from other domestic areas. As for DEHP and DnBP, though both were obviously lower than those in soil irrigated by industrial wastewater in Beijing $(59.8 \mathrm{mg} / \mathrm{kg}$ for DnBP and $16.8 \mathrm{mg} / \mathrm{kg}$ for DEHP; Zhao et al. 1982), the levels were comparable to greenhouse soil in Jinan, Shenyang and Beijing (Wang et al. 2002; Tang et al. 1993; Ma et al. 2003), where the plastic film has been used to improve the output of farm produce. As for DOP, the content was lower than that in vegetable soil of Jinan suburb $(0.8 \mathrm{mg} / \mathrm{kg}$; Meng et al. 1996) and was close to those in greenhouse soil of Beijing (Ma et al. 2003) and in rural soil of Beijing (Ma et al. 2004). The comparison above indicated that PAEs probably have caused serious contamination to urban soil in Beijing. It was worth noting that DEHP, DnBP, DiBP, $\sum 6$ EPA-PAEs and $\Sigma 7$ PAEs in urban soil were much higher than those in rural soil of Beijing (Ma et al. 2004), probably reflecting the significant 


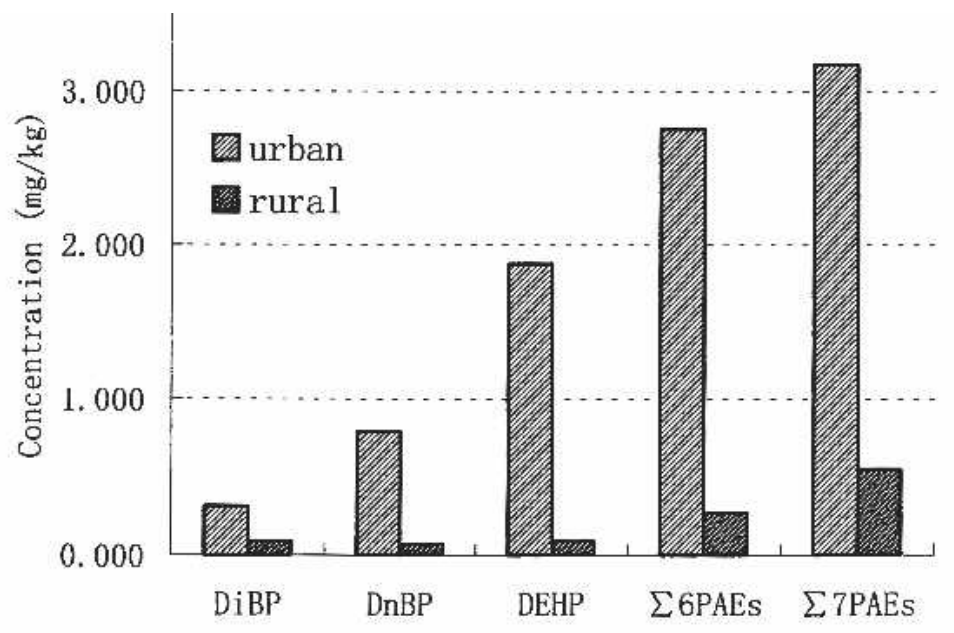

Figure 3. The comparison of PAEs between urban and rural soil

effect of anthropogenic activities. The similar results were reported at atmosphere of Beijing, where the level of PAEs in urban area was much higher than that in the rural area (Zhao et al. 1987). The comparison of PAEs between urban soil and rural soil was shown in Figure 3.

Due to the lack of environmental quality standard for soil about PAEs in China, the potential eco-toxicological effect of phthalates was assessed according to guide values and limits of soil from other countries. On the basis of the recommended Danish soil quality criteria (Jesen et al. 1994), the concentration of DnBP in all samples exceeded $100 \mu \mathrm{g} / \mathrm{kg}$ and that of DEHP in $63 \%$ samples exceeded $1000 \mu \mathrm{g} / \mathrm{kg}$, reflecting that the natural properties of soil have be affected in the studied area. Taking the endocrine disruptive properties of PAEs into account, the environmental risk limits for DnBP and DEHP in soil and sediment were considered as $0.7 \mathrm{mg} / \mathrm{kg}$ and $1.0 \mathrm{mg} / \mathrm{kg}$, respectively (Wezelare et al, 2000). The content of DnBP in $66 \%$ samples and that of DEHP in $63 \%$ samples were above this standard, indicating that PAEs in urban soil of Beijing could probably cause long-term eco-toxicological problem.

This paper revealed soil contamination situation by PAEs in urban area of Beijing. DnBP, DEHP and DiBP were the most common compositions in soil and both of $\mathrm{DnBP}$ and DEHP have disturbed the natural properties of soil, probably resulting in the eco-toxicological effect on environment of Beijing. The study also prompted us to monitor such pollutants in the urban soil to minimize the threat of phthalate pollution to the ecosystem and to human health.

Acknowledgments. This work was supported by Major State Basic Research Program of China (No.G 1999045707) and the Knowledge Innovation Program of 
the Chinese Academy of Sciences (RCEES 9902, 9906).

\section{REFERENCES}

Stales CA, Peterson DR, Parkerton TF, Adams WJ (1997) The environmental fate of phthalate esters: A literature review. Chemosphere 25: 667-749.

Du B, Zhang P, Zhang Z, Yu G (2004) Preliminary investigation on endocrine disrupting chemicals in a sewage treatment plant of Beijing. Environ Sci 25: 114-116 (in Chinese).

Keith LH, Telliard WA (1979) Priority pollutants. Environ Sci Technol 13: 416-419.

Latini G (2005) Monitoring phthalate exposure in humans. Clin Chim Acta 361: $20-29$.

Liu XY, Feng YJ, Liu LH, Yan GY, Fan YQ (2004) Investigation of organic pollutants in water in Yellow River. Water Source Protect 2: 37-38,56.

Ma LL (2004) Study of the organic pollution in soils on Beijing suburbans. Ph.D. Thesis, Research Center for Eco-Environmental Sciences, the Chinese Academy Sciences, Beijing.

Ma LL, Chu SG, Xu XB (2003) Phthalate residues in greenhouse soil from Beijing suburbs, People's Republic of China. Bull Environ Contam Toxicol 71: 394-399.

Meng P, Wang X, Xu G, Wang X, Li H (1996) Determination and distribution of phthalate alkyl esters in soil in Jinan. Environ Chem 15: 427-432 (in chinese).

Wezelare PV, Posthumus R, Crommentuijn GH, Sijm DTHM (2000) Environmental risk limits for two phthalates, with special emphasis on disruptive properties. Ecotoxicol Environ Saf 46: 305-321.

Jesen S, Eiksson G, Kylin H (1997) The environmental fate of phthalates: a literature review. Chemosphere 35: 667-749.

Shanker R, Ramarkrishna C, Sech PK (1985) Degradation of some phthalic acid esters in soil. Environ Pollut 39: 1-7.

Sun J, Zhang K, Wu D, Liang M (2002) Investigation of phthalates in disposable plastic products. J Environ Health 19:314-315 (in Chinese).

Tang GC, Cai YQ, Wang SL (1993) Study of phthalate ester residues in farmland in Shenyang. Rural Eco-Environ 3: 36-39(in Chinese).

Wang L, Luo N, Zhang C (2004) The detection of lytic phthalate esters DBP and DEHP from the plastic tucher-bag. J Tongji Univ (Medical science), 5: 15-17 (in Chinese).

Wang XK, Guo WL, Meng PR, Gan JA (2002) Analysis of phthalate esters in air, soil and plants in plastic film greenhouse. Chinese Chem Lett 13:557-560 (in Chinese).

Wei A, Zhao G, Liu X, Xue J, Wang X, Yu M, Sun S (1986) Organic pollutants in ground water in Beijing-Tianjin area. Acta Scientiae Circumstantiae 6: 293-305 (in Chinese).

Yu LP, Gao GH (1997) Advance of plastic additives in China. Technoleconom Petrochem 13: 26 (in Chinese).

Zeng F (2003) Qualitative and Quantitative Study of phthalic ester hormone from the atmosphere. Journal of the CUN (Natural Sciemces Edition) 12: 151-153 
(in Chinese).

Zhang Y, Chen B, Zheng L, Wu X (2003) Study on the level of phthalates in human biological samples. Chin J Pre Med 37: 429-434 (in Chinese).

Zhao Z, Xu ZF, Phthalate esters in the atmosphere and soil of Beijing. Environ Sci. 1982,1: 461-466 (in Chinese).

Zhao Z, Quan WY, Tian DH (1987) Phthalate esters in the atmosphere particulates of Beijing urban area. Environ Sci 6: 29-34 (in Chinese). 